\title{
Cost-utility analysis of percutaneous mitral valve repair in inoperable patients with functional mitral regurgitation in German settings
}

Oleg Borisenko ${ }^{1 *}$, Michael Haude$^{2}$, Uta C Hoppe ${ }^{3}$, Tomasz Siminiak $^{4}$, Janusz Lipiecki ${ }^{5}$, Steve L Goldberg ${ }^{6}$, Nawzer Mehta ${ }^{7}$, Omari V Bouknight ${ }^{7}$, Staffan Bjessmo ${ }^{1,8}$ and David G Reuter ${ }^{9}$

\begin{abstract}
Background: To determine the cost-effectiveness of the percutaneous mitral valve repair (PMVR) using Carillon ${ }^{\circledR}$ Mitral Contour System ${ }^{\oplus}$ (Cardiac Dimensions Inc., Kirkland, WA, USA) in patients with congestive heart failure accompanied by moderate to severe functional mitral regurgitation (FMR) compared to the prolongation of optimal medical treatment (OMT).

Methods: Cost-utility analysis using a combination of a decision tree and Markov process was performed. The clinical effectiveness was determined based on the results of the Transcatheter Implantation of Carillon Mitral Annuloplasty Device (TITAN) trial. The mean age of the target population was 62 years, $77 \%$ of the patients were males, $64 \%$ of the patients had severe FMR and all patients had New York Heart Association functional class III. The epidemiological, cost and utility data were derived from the literature. The analysis was performed from the German statutory health insurance perspective over 10-year time horizon.

Results: Over 10 years, the total cost was $€ 36,785$ in the PMVR arm and $€ 18,944$ in the OMT arm. However, PMVR provided additional benefits to patients with an 1.15 incremental quality-adjusted life years (QALY) and an 1.41 incremental life years. The percutaneous procedure was cost-effective in comparison to OMT with an incremental cost-effectiveness ratio of $€ 15,533 / \mathrm{QALY}$. Results were robust in the deterministic sensitivity analysis. In the probabilistic sensitivity analysis with a willingness-to-pay threshold of €35,000/QALY, PMVR had a $84 \%$ probability of being cost-effective.
\end{abstract}

Conclusions: Percutaneous mitral valve repair may be cost-effective in inoperable patients with FMR due to heart failure.

Keywords: Heart failure, Functional mitral regurgitation, Percutaneous valve repair treatment, Cost-utility analysis, Germany

\section{Background}

Functional mitral regurgitation (FMR) is a common condition that can occur secondary to systolic heart failure and dilated left ventricular cardiomyopathy [1-4]. The cornerstone of clinical management is medical therapy with surgical valve replacement or repair, which is not possible in severely diseased patients with contraindications to surgery and general anesthesia $[5,6]$. Although FMR can lead to increased mortality, reduced functional capacity and increased healthcare cost, only a few targeted treatments,

\footnotetext{
* Correspondence: oleg.borisenko@synergus.com

'Synergus AB, Svardvagen 19, 18233 Danderyd, Sweden

Full list of author information is available at the end of the article
}

addressing FMR, are available. There is ongoing debate about the optimal intervention for FMR, its timing and effectiveness [7-11].

The Carillon ${ }^{\circ}$ Mitral Contour System ${ }^{\circ}$ (Cardiac Dimensions Inc., Kirkland, WA, USA) is a novel percutaneous coronary sinus-based mitral annuloplasty device designed to treat FMR. This approach has been shown to significantly reduce FMR, improve functional capacity and quality of life as well as induce reverse left ventricular remodeling [12-14]. Given these findings and the high prevalence of patients with heart failure and FMR, it is important to understand the economic implications of percutaneous mitral valve repair (PMVR). After safety, efficacy and 
effectiveness aspects, cost-effectiveness is becoming the fourth hurdle for reimbursement of novel technologies in most developed countries [15-17]. The current clinical evidence for CE-marked Carillon ${ }^{\circ}$ Mitral Contour System ${ }^{\circ}$ is based on the single arm AMADEUS [12] and the non-randomized controlled Transcatheter Implantation of Carillon Mitral Annuloplasty Device (TITAN) [13] trials, which makes it possible to perform an early economic evaluation to inform decision-making about the cost-effectiveness of PMVR and ensure the timely access of patients to this treatment option.

The objective of the study was to determine, in German settings, the cost-effectiveness of PMVR using the Carillon ${ }^{\circ}$ Mitral Contour System ${ }^{\circ}$ in patients with congestive heart failure and moderate to severe FMR with normal QRS interval, compared with the prolongation of optimal medical treatment.

\section{Methods}

\section{Model description}

The combination of a decision tree and a Markov process [18-20] was used to assess the economic value of percutaneous annuloplasty in patients with FMR. The cycle length was one month. The model starts with a decision tree (Fig. 1), in which the patients undergoing PMVR may have several possible outcomes, including discharge from the hospital without complications, perioperative complications with subsequent discharge from the hospital, unsuccessful device implantation with subsequent removal of the device during the initial procedure or death. All serious complications related to the implantation procedure were selected from the published TITAN trial [13]. During the first month of the model, the patients in the optimal medical treatment arm could die or stay alive. Decision tree estimates the cost-effectiveness for the first month in the model. Thereafter, all patients in both arms entered the Markov model.

The structure of the follow-up Markov model was applied to both treatment arms. The Markov model consists of four health states representing the four New York Heart Association (NYHA) functional classes. Patients may progress from one NYHA class to another. In each state, hospitalization and death are possible. The probability of hospitalization and death is higher with increasing NYHA classes. Each state of the Markov model has associated cost and utility based on the status of health-related quality of life.

The basis for the analysis is that PMVR, by improving symptoms (i.e., improving the patient's NYHA functional class) through the reduction of FMR, will reduce both mortality and hospitalizations compared with the prolongation of optimal medical treatment.

\section{Clinical inputs}

Search for relevant clinical, cost and utility inputs was performed in the Medline database using key words "functional mitral regurgitation", "prognosis", "mortality", "cost", "NYHA class" in April 2012 and repeated in August 2014.

Monthly transition probabilities across NYHA classes for the Carillon and optimal medical therapy arms (Table 1) were derived from the TITAN trial [13]. The TITAN trial enrolled fifty-three patients with dilated ischemic or non-ischemic cardiomyopathy from seven European centers. The inclusion criteria were 1) at least moderate $(2+)$ FMR, 2) a left ventricular ejection fraction $($ LVEF) $<40 \%$, 3) NYHA class II-IV, 4) a 6 min walk

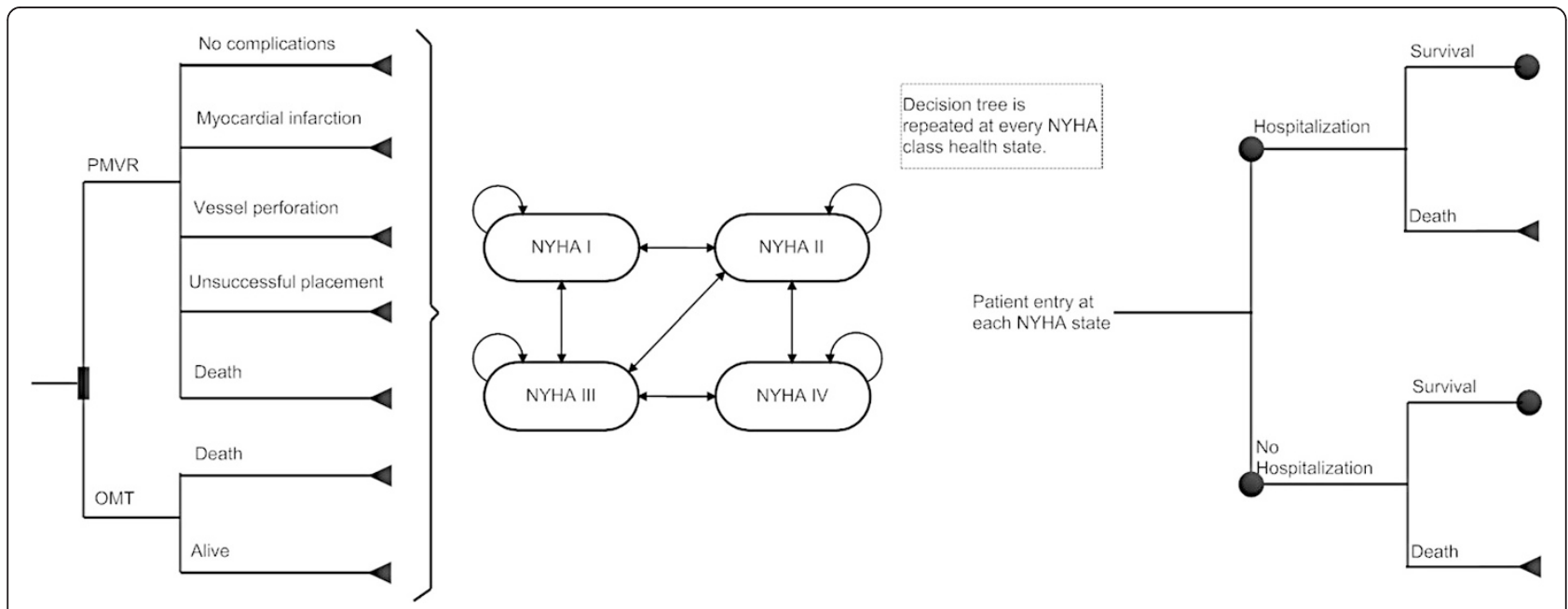

Fig. 1 Decision tree and Markov model structure. NYHA, New York Heart Association; OMT, optimal medical treatment; PMVR, percutaneous mitral valve repair 
Table 1 Transition probabilities between NYHA functional classes [13]

\begin{tabular}{|c|c|c|c|c|}
\hline \multicolumn{5}{|c|}{ Transition probabilities in cycle 1} \\
\hline & NYHA I & NYHA ॥ & NYHA III & NYHA IV \\
\hline \multicolumn{5}{|c|}{ Optimal medical treatment arm } \\
\hline NYHA Class III & 0.00 & 0.17 & 0.75 & 0.08 \\
\hline \multicolumn{5}{|l|}{ PMVR arm } \\
\hline NYHA Class III & 0.10 & 0.73 & 0.13 & 0.03 \\
\hline \multicolumn{5}{|c|}{ Transition probabilities in cycles $2-11$} \\
\hline & NYHA I & NYHA $\|$ & NYHA III & NYHA IV \\
\hline \multicolumn{5}{|c|}{ Optimal medical treatment arm } \\
\hline NYHA Class I & 0.00 & 0.00 & 0.00 & 0.00 \\
\hline NYHA Class II & 0.00 & 0.67 & 0.00 & 0.33 \\
\hline NYHA Class III & 0.00 & 0.17 & 0.83 & 0.00 \\
\hline NYHA Class IV & 0.00 & 0.00 & 0.17 & 0.83 \\
\hline \multicolumn{5}{|l|}{ PMVR arm } \\
\hline NYHA Class I & 0.25 & 0.75 & 0.00 & 0.00 \\
\hline NYHA Class II & 0.11 & 0.63 & 0.26 & 0.00 \\
\hline NYHA Class III & 0.00 & 0.50 & 0.50 & 0.00 \\
\hline NYHA Class IV & 0.00 & 0.00 & 0.50 & 0.50 \\
\hline \multicolumn{5}{|c|}{ Transition probabilities in cycle 12 and onwards } \\
\hline & NYHA I & NYHA $\|$ & NYHA III & NYHA IV \\
\hline \multicolumn{5}{|c|}{ Optimal medical treatment arm } \\
\hline NYHA Class I & 0.00 & 0.00 & 0.00 & 0.00 \\
\hline NYHA Class II & 0.00 & 0.50 & 0.50 & 0.00 \\
\hline NYHA Class III & 0.00 & 0.67 & 0.33 & 0.00 \\
\hline NYHA Class IV & 0.00 & 0.00 & 0.67 & 0.33 \\
\hline \multicolumn{5}{|l|}{ PMVR arm } \\
\hline NYHA Class I & 0.67 & 0.33 & 0.00 & 0.00 \\
\hline NYHA Class II & 0.12 & 0.71 & 0.18 & 0.00 \\
\hline NYHA Class III & 0.00 & 0.40 & 0.60 & 0.00 \\
\hline NYHA Class IV & 0.00 & 0.00 & 0.40 & 0.60 \\
\hline
\end{tabular}

NYHA, New York Heart Association; PMVR, percutaneous mitral valve repair

distance between 150 and $450 \mathrm{~m}$ and 5) a stable heart failure medication regimen. Thirty-six patients underwent permanent device implantation and seventeen patients had the device recaptured intra-operatively (i.e., device was removed) either for clinical indications (i.e., transient coronary compromise) or for a protocol defined indication (i.e., <1 grade FMR reduction). Both groups underwent serial follow-ups with the non-implanted cohort serving as a non-randomized, non-blinded comparator group. Data for 17 patients with device recaptured after unsuccessful implantation have been used to obtain transition probabilities in the optimal medical management (control) arm in the model. Compared with the control group, clinically and statistically significant reduction in FMR (regurgitant volume, effective regurgitant orifice area (EROA), vena contracta, mitral regurgitation jet area/left atrial area) was demonstrated. Different transition probabilities were applied for the first month, for months 2 to 11 , and from month 12 and onwards. As the TITAN trial provided limited data about the transitions from NYHA class IV to other classes, an assumption was made about these transitions being similar to transitions from NYHA class III. It was assumed that NYHA class I does not lead to increased mortality. Clinical inputs are presented in Table 2.

The probability of hospitalization due to worsening of heart failure was derived from the literature [21]. Ageand gender-specific general mortality was derived from German life tables [6]. Excessive all-cause mortality in relation with the NYHA class was also derived from the literature [22].

Functional mitral regurgitation is an independent predictor of mortality and hospitalization in patients with chronic heart failure [23-25]. In the model, the additional risk of mortality and hospitalization in patients with severe FMR versus patients with mild/moderate FMR or no FMR was introduced. Functional mitral regurgitation was classified as mild/moderate with an effective regurgitant orifice area (EROA) $\leq 0.2 \mathrm{~cm}^{2}$ and as severe with an EROA $\geq 0.2 \mathrm{~cm}^{2}$.

Patients in the PMVR arm experienced a decrease in FMR and an improvement in NYHA class starting the 1st month after the treatment. The long-term follow-up of these patients (3 years) has demonstrated a stable and durable effect of PMVR over time and, therefore, a sustained FMR reduction was assumed. According to the results of the TITAN trial, the patients in the control group had no improvement in FMR.

An intention-to-treat approach was used to simulate disease progression in the patients with unsuccessful device placement. In this sub-group, the degree of FMR and the NYHA functional classes were similar to the optimal medical treatment arm.

\section{Resource utilization and cost data}

All resource use and cost data were derived from German sources (Table 2). The cost of PMVR was calculated from relevant German diagnosis-related group (DRG) (F19C) with the subtracted cost of implant and the added cost of the Carillon device. Peri-operative myocardial infarction was reported among the 20 most prevalent secondary diagnoses for the DRG, and it was assumed that no additional cost was incurred to manage this event. Based on clinical opinions, 14 additional days of hospital stay would be needed to treat a coronary sinus perforation. The basic DRG tariff covers the treatment for 2 to 10 days of hospital stay (average of 5.2 days). Therefore, incremental costs were applied only for the extra days of hospital stay necessary to treat a vessel perforation. The cost of the device and 
Table 2 Clinical, cost and utility inputs

\begin{tabular}{|c|c|c|c|c|}
\hline Variable & $\begin{array}{l}\text { Base Case } \\
\text { Value }\end{array}$ & Range & $\begin{array}{l}\text { Distribution for probabilistic } \\
\text { sensitivity analysis }\end{array}$ & Reference \\
\hline \multicolumn{5}{|l|}{ Characteristics of patients' population } \\
\hline \multirow[t]{2}{*}{ Age, years } & 62 & $50-80$ & Normal & [13] \\
\hline & & & $(\mathrm{SD}=12)$ & \\
\hline Male gender, \% & 77 & $0-100$ & Beta & \\
\hline \multirow{2}{*}{$\begin{array}{l}\text { Proportion of patients with severe MR } \\
\text { at baseline in both arms }\end{array}$} & 0.639 & $0.511-0.766$ & Beta & \\
\hline & & & $(a=23 ; \beta=13)$ & \\
\hline \multirow{2}{*}{$\begin{array}{l}\text { Proportion of patients with severe MR } \\
\text { between } 1 \text { and } 5 \text { months in PMVR arm }\end{array}$} & 0.35 & $0.28-0.42$ & Beta & \\
\hline & & & $(a=12 ; \beta=22)$ & \\
\hline \multirow{2}{*}{$\begin{array}{l}\text { Proportion of patients with severe MR } \\
\text { from } 6 \text { months and onwards in PMVR arm }\end{array}$} & 0.258 & $0.206-0.309$ & Beta & \\
\hline & & & $(a=8 ; \beta=23)$ & \\
\hline \multicolumn{5}{|l|}{ Effectiveness data and transition probabilities } \\
\hline \multirow[t]{2}{*}{ Probability of peri-procedural mortality } & 0.019 & $0.01-0.03$ & Beta & [13] \\
\hline & & & $(a=1 ; \beta=52)$ & \\
\hline \multirow{2}{*}{$\begin{array}{l}\text { Probability of myocardial infarction, which } \\
\text { leads to PCl }\end{array}$} & 0.04 & $0.02-0.06$ & Beta & \\
\hline & & & $(a=2 ; \beta=51)$ & \\
\hline \multirow[t]{2}{*}{ Probability of vessel perforation } & 0.02 & $0-0.03$ & Beta & \\
\hline & & & $(a=1 ; \beta=52)$ & \\
\hline \multirow{2}{*}{$\begin{array}{l}\text { Probability of unsuccessful percutaneous } \\
\text { annuloplasty }\end{array}$} & 0.32 & $0.05-0.40$ & Beta & \\
\hline & & & $(a=17 ; \beta=36)$ & \\
\hline \multirow[t]{2}{*}{ Probability of arrhythmia } & 0.04 & $0.02-0.06$ & Beta & Assumption \\
\hline & & & $(a=2 ; \beta=51)$ & \\
\hline \multirow{2}{*}{$\begin{array}{l}\text { Six-month probability of excess mortality for } \\
\text { NYHA class } \|\end{array}$} & 0.04 & $0.02-0.06$ & Beta & {$[22]$} \\
\hline & & & $(a=4 ; \beta=96)$ & \\
\hline \multirow{2}{*}{$\begin{array}{l}\text { Six-month probability of excess mortality for } \\
\text { NYHA class III }\end{array}$} & 0.07 & $0.035-0.105$ & Beta & \\
\hline & & & $(a=7 ; \beta=93)$ & \\
\hline \multirow{2}{*}{$\begin{array}{l}\text { Six-month probability of excess mortality for } \\
\text { NYHA class IV }\end{array}$} & 0.28 & $0.14-0.42$ & Beta & \\
\hline & & & $(a=28 ; \beta=72)$ & \\
\hline \multirow{2}{*}{$\begin{array}{l}\text { Monthly probability of hospitalization for } \\
\text { NYHA class I }\end{array}$} & 0.015 & $0.008-0.023$ & Beta & [21] \\
\hline & & & $(a=1.5 ; \beta=98.5)$ & \\
\hline \multirow{2}{*}{$\begin{array}{l}\text { Monthly probability of hospitalization for } \\
\text { NYHA class II }\end{array}$} & 0.024 & $0.012-0.036$ & Beta & \\
\hline & & & $(a=2.4 ; \beta=97.6)$ & \\
\hline \multirow{2}{*}{$\begin{array}{l}\text { Monthly probability of hospitalization for } \\
\text { NYHA class III }\end{array}$} & 0.024 & $0.012-0.036$ & Beta & \\
\hline & & & $(a=2.4 ; \beta=97.6)$ & \\
\hline \multirow{2}{*}{$\begin{array}{l}\text { Monthly probability of hospitalization for } \\
\text { NYHA class IV }\end{array}$} & 0.154 & $0.077-0.231$ & Beta & \\
\hline & & & $(a=15.4 ; \beta=84.6)$ & \\
\hline
\end{tabular}


Table 2 Clinical, cost and utility inputs (Continued)

\begin{tabular}{|c|c|c|c|c|}
\hline $\begin{array}{l}\text { Relative risk for all-cause mortality with } \\
\text { present severe MR }\end{array}$ & 1.5 & $1.1-1.9$ & Log-normal $\left(\mathrm{SE}_{\mathrm{log}}=0.26\right)$ & [23] \\
\hline $\begin{array}{l}\text { Relative risk for hospitalization due to } \\
\text { HF with present severe MR }\end{array}$ & 1.7 & $1.3-2.1$ & Log-normal $\left(\mathrm{SE}_{\mathrm{log}}=0.33\right)$ & \\
\hline \multicolumn{5}{|l|}{ Resource utilization and cost data } \\
\hline Cost of Carillon device, $€$ & 18,000 & $12,600-23,400$ & - & Cardiac Dimensions, Inc. \\
\hline Cost of PMVR placement procedure, $€$ & 4844 & $3391-6297$ & - & G-DRG code F19C \\
\hline $\begin{array}{l}\text { Cost of treatment of vessel perforation } \\
\text { after PMVR placement, } €\end{array}$ & 1998 & 1399-2597 & - & \\
\hline $\begin{array}{l}\text { Percentage of patients being hospitalized } \\
\text { with stay in intensive care unit }\end{array}$ & $7.2 \%$ & - & Dirichlet & [27] \\
\hline $\begin{array}{l}\text { Percentage of patients being hospitalized } \\
\text { with stay in coronary care unit }\end{array}$ & $25.6 \%$ & - & & \\
\hline $\begin{array}{l}\text { Percentage of patients being hospitalized } \\
\text { with CABG performed }\end{array}$ & $0.3 \%$ & - & & \\
\hline $\begin{array}{l}\text { Percentage of patients being hospitalized } \\
\text { with PTCA performed }\end{array}$ & $0.2 \%$ & - & & \\
\hline $\begin{array}{l}\text { Percentage of patients being hospitalized } \\
\text { with heart transplantation performed }\end{array}$ & $2.6 \%$ & - & & \\
\hline $\begin{array}{l}\text { Percentage of patients being hospitalized } \\
\text { with no procedure performed }\end{array}$ & $62.3 \%$ & - & & \\
\hline $\begin{array}{l}\text { Cost of hospitalization with stay in intensive } \\
\text { care unit, } €\end{array}$ & 5004 & $3503-6506$ & - & G-DRG code F62A 2013 \\
\hline $\begin{array}{l}\text { Cost of hospitalization with stay in coronary } \\
\text { care unit, } €\end{array}$ & 5004 & $3503-6506$ & - & G-DRG code F62A 2013 \\
\hline $\begin{array}{l}\text { Cost of hospitalization with CABG } \\
\text { performed, } €\end{array}$ & 15,056 & $10,539-19,573$ & - & G-DRG code F06E \\
\hline $\begin{array}{l}\text { Cost of hospitalization with PTCA } \\
\text { performed, } €\end{array}$ & 3793 & $2655-4931$ & - & G-DRG code F56B plus ZE101 \\
\hline $\begin{array}{l}\text { Cost of hospitalization with heart } \\
\text { transplantation performed, } €\end{array}$ & 86,337 & $60,436-112,239$ & - & G-DRG code A05B 2013 \\
\hline $\begin{array}{l}\text { Cost of hospitalization with no procedure } \\
\text { performed, } €\end{array}$ & 2740 & 1918-3562 & - & G-DRG code F62B 2013 \\
\hline \multirow{2}{*}{$\begin{array}{l}\text { Annual cost of routine management of heart } \\
\text { failure in NYHA class I, } €\end{array}$} & 495 & 258-1031 & Gamma & [26] \\
\hline & & & $(a=1 ; \lambda=516)$ & \\
\hline \multirow{2}{*}{$\begin{array}{l}\text { Annual cost of routine management of heart } \\
\text { failure in NYHA class } \| \text {, } €\end{array}$} & 874 & $455-1821$ & Gamma & \\
\hline & & & $(a=1 ; \lambda=910)$ & \\
\hline \multirow{2}{*}{$\begin{array}{l}\text { Annual cost of routine management of heart } \\
\text { failure in NYHA class III, } €\end{array}$} & 864 & $450-1800$ & Gamma & \\
\hline & & & $(a=1 ; \lambda=900)$ & \\
\hline \multirow{2}{*}{$\begin{array}{l}\text { Annual cost of routine management of heart } \\
\text { failure in NYHA class IV, } €\end{array}$} & 929 & 484-1935 & Gamma & \\
\hline & & & $(a=1 ; \lambda=967)$ & \\
\hline \multicolumn{5}{|l|}{ Utility data } \\
\hline \multirow[t]{2}{*}{ Utility for NYHA I class } & 0.815 & $0.652-0.978$ & Beta & [27] \\
\hline & & & $(a=395 ; \beta=90)$ & \\
\hline \multirow[t]{2}{*}{ Utility for NYHA II class } & 0.720 & $0.576-0.864$ & Beta & \\
\hline & & & $(a=662 ; \beta=257)$ & \\
\hline Utility for NYHA III class & 0.590 & $0.472-0.708$ & Beta & \\
\hline
\end{tabular}


Table 2 Clinical, cost and utility inputs (Continued)

\begin{tabular}{|c|c|c|c|c|}
\hline & & & $(a=360 ; \beta=250)$ & \\
\hline Utility for NYHA IV class & 0.508 & $0.406-0.609$ & Beta $(\alpha=52 ; \beta=50)$ & \\
\hline \multirow[t]{2}{*}{$\begin{array}{l}\text { Decrement for percutaneous } \\
\text { annuloplasty procedure }\end{array}$} & 0.043 & $0.034-0.051$ & Beta & [29] \\
\hline & & & $(a=96 ; \beta=2129)$ & \\
\hline
\end{tabular}

SD, standard deviation; MR, mitral regurgitation; PMVR, percutaneous mitral valve repair; NYHA, New York Heart Association

procedure for the cases of unsuccessful implantation was included in the analysis and was assumed to be covered by the statutory health insurance.

The cost of routine management of heart failure (including the costs of physician, medication and rehabilitation) according to the NYHA class was derived from a recent analysis from the German Competence Network Heart Failure [26]. The costs of hospitalization in the intensive care unit and coronary care unit and the costs of coronary artery bypass grafting, percutaneous transluminal coronary angioplasty, heart transplantation and no invasive procedures were derived from relevant German DRGs. The proportion of hospitalized patients undergoing invasive treatment and the type of invasive treatment were extrapolated from the CARE-HF trial [27].

Only the direct costs were included and were presented in 2013 Euros. The inflation adjustment was performed using the German consumer price index [28].

\section{Utility data}

Utility scores were assigned for each NYHA class irrespective of the treatment received and the hospitalization status. Utility values were derived from the CARE-HF trial [27]. A one-month utility decrement was applied to the Carillon implantation procedure which assumes a similar reduction in the quality of life after percutaneous coronary intervention $(0.043)$ [29].

\section{Base-case analysis}

The analysis was performed from the perspective of the German statutory health insurance over a 10-year time horizon.

The characteristics of the modeled cohort were primarily derived from the TITAN trial: the mean age was 62 years (SD 12 years), $77 \%$ were males, all patients had a NYHA class III (as average NYHA class was $3.0 \pm 0.24$ in the TITAN trial) and $63 \%$ had severe (MR 4+) FMR.

The incremental cost-effectiveness ratio (ICER) was calculated by comparing the difference in the average total costs and the difference in the average qualityadjusted life years (QALY) among the model's arms. The intervention was considered cost-effective if the ICER was below the willingness-to-pay threshold of $€ 35,000$ / QALY [30, 31]. All costs and outcomes beyond the first year were discounted by $3.0 \%$ annually following the recommendations of the German Institute for Quality and Efficiency in Health Care (IQWIG) [32]. The model was constructed in Microsoft Excel 2010 (Microsoft Corp., Redmond, Washington, USA).

\section{Model validation}

After confirming the validity of the results, a number of "stress tests" were performed to evaluate the technical performance of the model. Subsequently, the results of the analysis (all-cause mortality at different follow-ups) were compared with data from the TITAN trial as well as two epidemiological studies of patients with FMR [23, 25].

\section{Sensitivity analysis}

A one-way sensitivity analysis was performed to assess the impact of varying the model parameters while holding other variables fixed at base-case values. The major cost drivers were identified and the results of the sensitivity analysis results were presented by means of a Tornado diagram. In addition, analysis of fade-out effect for PMVR was performed with transition probabilities between NYHA classes in PMVR arm being equal to OMT arm after 3 years from the start of analysis (as maximum length of observation in Carillon studies is 3 years [33]). In addition to the base-case analysis over 10-year time horizon, cost-effectiveness of PMVR was also estimated over a lifetime horizon.

A probabilistic sensitivity analysis was also performed with 5000 Monte Carlo simulations. A beta distribution was used for the probabilities and utility values, a dirichlet distribution was used for the probabilities of transition between NYHA classes and proportions of patients receiving different treatments during hospitalization, and a log-normal distribution was used for the relative risk. DRG tariffs and cost of PMVR were not tested in probabilistic sensitivity analysis, as there was no uncertainty associated with them.

\section{Ethics statement}

Approval by ethics committee was not required, as study did not involve human material or human data. 


\section{Results}

\section{Model validation}

Validation of the model showed that the model could precisely predict all-cause mortality at one, two and five years of follow-up (Fig. 2).

\section{Base-case analysis}

Over 10 years, the total cost in the PMVR arm was $€ 36,785$ and $€ 18,944$ in the optimal medical treatment arm (Table 3). Percutaneous mitral valve repair, however, provided a significant benefit to the patients compared with the optimal medical treatment (1.15 incremental QALYs and 1.41 incremental life years). Cumulative mortality was $13.8 \%$ and $23.5 \%$ at 1 year, $20.0 \%$ and $33.0 \%$ at 2 years, $35.6 \%$ and $54.3 \%$ at 5 years, and $55.5 \%$ and $76.5 \%$ at 10 years in the PMVR and optimal medical treatment arms respectively.

The percutaneous mitral valve repair treatment was cost-effective in comparison to optimal medical treatment with an ICER of $€ 15,533 /$ QALY.

\section{Sensitivity analysis}

The results of the one-way sensitivity analysis were stable with no single variable altering the cost-effectiveness of PMVR (Fig. 3). The most sensitive variables were the cost of the Carillon device, the age of the patient, the probability of unsuccessful annuloplasty and the presence of severe FMR at baseline.

In the analysis over lifetime horizon PMVR led to incremental cost of $€ 19,539$, incremental life-years gained of 3.23 and QALYs gained of 2.47. PMVR was more cost-effective over lifetime (ICER of $€ 7,914 / \mathrm{QALY}$ ) compared with base-case analysis over 10-year time horizon.

Analysis of fade-out effect for effectiveness of PMVR showed that technology remains cost-effective with ICER of $€ 23,582 / Q A L Y$. In this analysis, PMVR led to an incremental cost of $€ 20,662$ (cost of $€ 39,702$ and $€ 19,040$ in the PMVR and optimal medical management arms respectively), an incremental life years gained of 1.04 (life years gained of 5.49 and 4.46 in the PMVR and optimal medical management arms respectively) and an incremental QALYs gained of 0.88 (QALYs gained of 3.78 and 2.90 in the PMVR and optimal medical management arms respectively).

In the probabilistic sensitivity analysis with 5000 simulations, PMVR led to an incremental cost of $€ 14,868$, an incremental life-years gained of 0.81 and a QALYs gained of 0.77 (Fig. 4). Percutaneous mitral valve repair was costeffective compared with optimal medical treatment with an ICER of $€ 19,414 /$ QALY. At a willingness-to-pay threshold of $€ 35,000 / Q A L Y$, PMVR had a $84 \%$ probability of being cost-effective (Fig. 5). At a threshold of $€ 50,000 / Q A L Y$, PMVR had a $93 \%$ probability of being cost-effective.

\section{Discussion}

Patients with left ventricular dysfunction and FMR have a poor prognosis $[2,3,24,25,34]$. In severely ill patients, the number of treatment options is limited. A survey of European patients with heart failure and mitral regurgitation revealed that the determinants of preclusion of surgical treatment include impaired LVEF, older age and comorbidities [35], which are typical for heart failure patients with FMR.

Furthermore, patients with FMR have a normal mitral apparatus because the pathophysiological mechanism leading to mitral regurgitation is left ventricular dilatation with the subsequent mal-coaptation of the mitral leaflets. This has resulted in the ongoing evaluation of an array of non-surgical methods to attempt to correct mal-coaptation $[5,36]$.

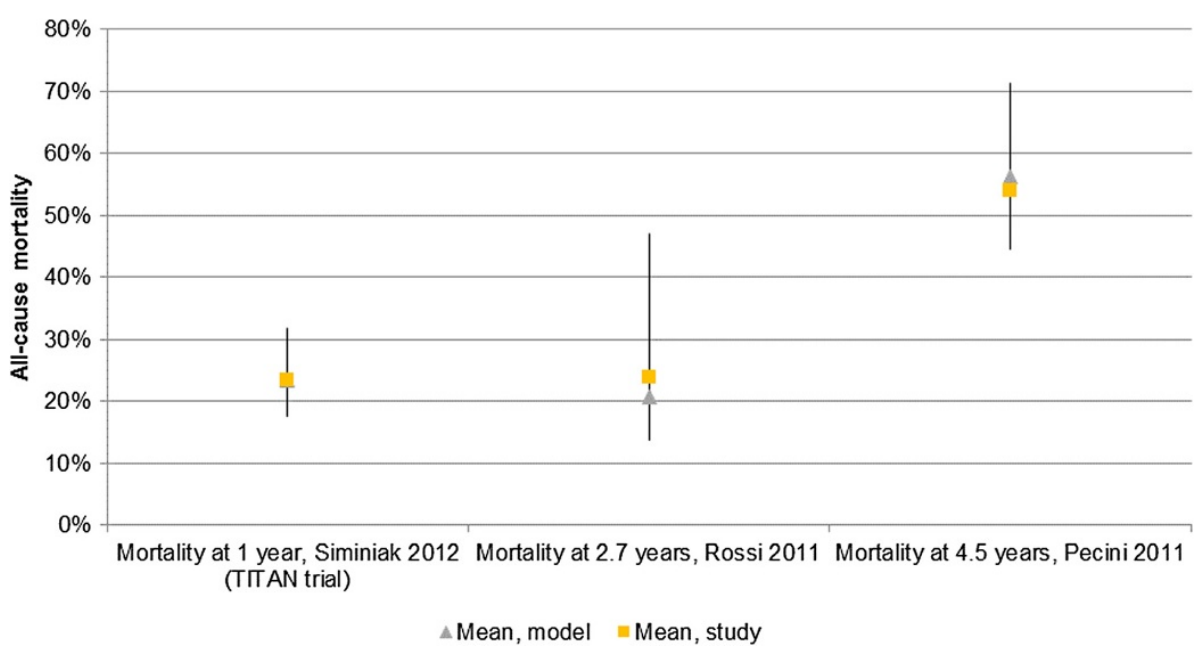

Fig. 2 Results of the model validation. Scares represents the mean value from the validation study, triangles represent the mean value from the model, and lines represent the $95 \%$ credible interval for the modeled results 
Table 3 Results of the cost-utility analysis

\begin{tabular}{|c|c|c|c|c|c|c|c|}
\hline Treatment arm & Cost, $€$ & Incremental cost, $€$ & LYG & Incremental LYG & QALY gained & Incremental QALY gained & ICER, €/QALY \\
\hline Optimal medical treatment & 18,944 & & 4.46 & & 2.91 & & \\
\hline Percutaneous mitral valve repair & 36,785 & 17,841 & 5.87 & 1.41 & 4.06 & 1.15 & 15,533 \\
\hline
\end{tabular}

ICER - incremental cost-effectiveness ratio; LYG - life years gained; QALY - quality-adjusted life years

Our study showed that PMVR using Carillon ${ }^{\circ}$ Mitral Contour System ${ }^{\circ}$ leads to an incremental cost $(€ 17,841)$, but it also leads to significant additional clinical benefit to patients with increments of QALY and life-years of 1.15 and 1.41, respectively. Overall, PMVR can be costeffective in German settings with an ICER of $€ 15,533$ / QALY.

The model utilized a Markov process on the basis of four NYHA functional classes with each class sub-divided into hospitalized and non-hospitalized states. Many published decision analytic models in the field of heart failure have utilized NYHA classes to trace the progression of symptoms [22, 27, 37-39]. Hospitalizations are also a common determinant in economic evaluations, as they are one of the main cost drivers of heart failure. Studies have shown that hospitalizations account for $60-74 \%$ of the total expenditures of heart failure in France, the UK, The Netherlands, New Zealand and Sweden [40-42]. A recent analysis from Germany reports that the annual cost of heart failure in Germany totals $€ 2.8$ billion of which $€ 1.7$ billion is spent on in-patient facilities [43].

Results of the study are similar to published economic evaluations of another percutaneous treatment for mitral regurgitation, the MitraClip (Abbott Vascular, Santa Clara, California) [44, 45]. The analyses, based on the Endovascular Valve Edge-to-Edge REpair High Risk Study [46], were performed in the UK [44] and Canadian [45] settings and both compared the MitraClip to optimized medical treatment. In the UK study, over 10-year time horizon, the MitraClip lead to an incremental QALYs of 2.04 and a resulting ICER of $£ 14,800 / \mathrm{QALY}$. The Canadian study employed a lifetime horizon for its base-case analysis and reported an incremental QALYs of 1.73 and a resulting ICER of $\$ 23,433 /$ QALY. At a 10-year time horizon, the MitraClip was also cost-effective with an ICER of \$25,752/ QALY. In our study, a similar level of clinical benefits (incremental QALYs of 1.15) and cost-effectiveness (ICER of $€ 15,533$ /QALY) were demonstrated.

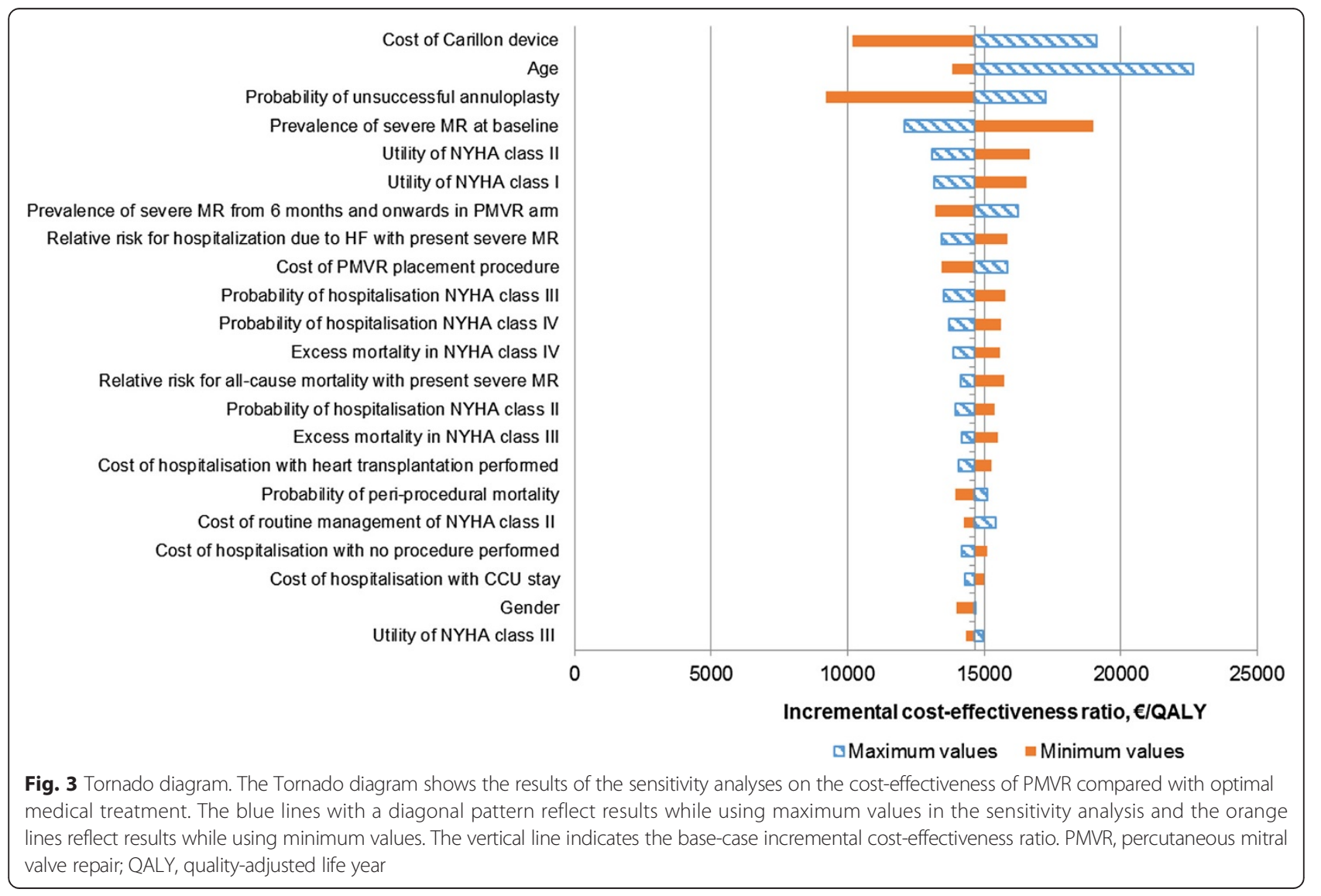




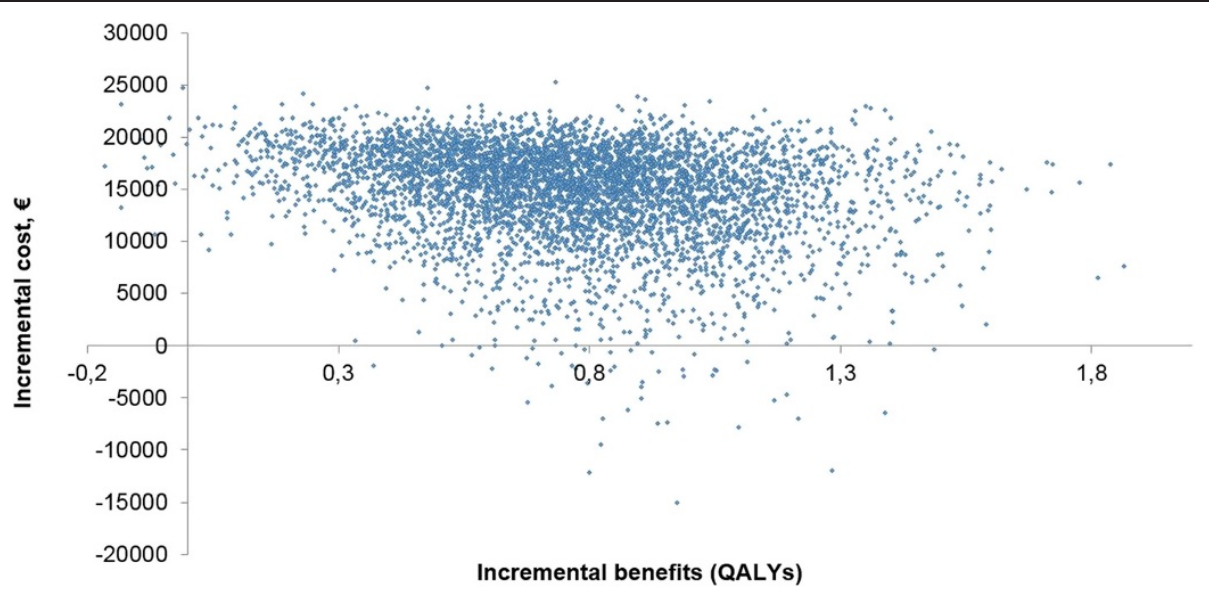

Fig. 4 Cost-effectiveness acceptability plane. QALY, quality-adjusted life year

Our study has several limitations. First, the transition probabilities between the different NYHA functional classes were based on a limited sample from the TITAN trial. Due to the limited sample size, not all transitions were possible in the base-case analysis. This limitation was addressed in the probabilistic sensitivity analysis. Second, the model utilized clinical and surrogate (mitral regurgitation) outcomes to predict mortality and hospitalization. Ideally, data on the impact of PMVR on mortality and hospitalizations as well as the utility data should be obtained directly from prospective randomized controlled trials rather than extrapolated from multiple sources. Evidence in the field of FMR is increasing and a more precise assessment may be possible in the future. A third limitation relates to the nature of the comparative effectiveness data for PMVR. Data about change of level of mitral regurgitation were obtained from the TITAN trial [13], in which the control group consisted of patients who underwent unsuccessful device placement, with explant of Carillon occurring during the procedure. Ideally, the effectiveness data should be obtained from a randomized controlled trial with an intention-to-treat analysis to allow the assessment of outcomes despite the real treatment received in groups with balanced observed and unobserved baseline characteristics. Nevertheless, in TITAN trial both groups had similar baseline demographic and clinical characteristics. However, due to the absence of random allocation into the treatment groups, there might be unobserved differences between groups, which may impact the reported effectiveness of PMVR. The TITAN trial had a sufficient follow-up period and the differences in the studied FMR measures at 1, 6 and 12 months between groups are not likely explained by reasons other than the impact of the implanted device. Finally, the maximum length of observation in Carillon studies is 3 years [28] while the clinical effectiveness was extrapolated over a 10-year time horizon in our

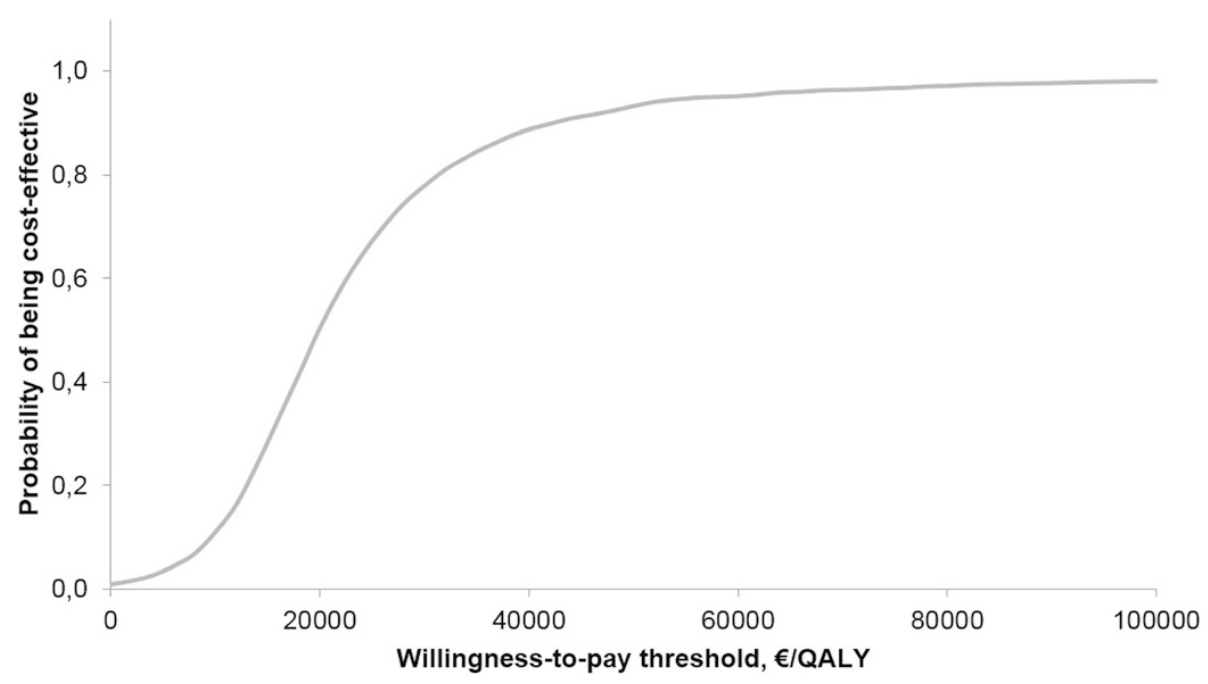

Fig. 5 Cost-effectiveness acceptability curve. QALY, quality-adjusted life year 
model. Nevertheless, analysis of fade-out effect for PMVR with effectiveness limited to 3 years showed that technology remains cost-effective in comparison with optimal medical treatment (ICER of $€ 23,582 / \mathrm{QALY}$ ). The aforementioned limitations should be taken into consideration when results of the present model are used to inform clinical or payer decision-makers.

\section{Conclusions}

When compared with optimal medical treatment, PMVR using the Carillon ${ }^{\circ}$ Mitral Contour System ${ }^{\circ}$ may be costeffective in inoperable patients with congestive heart failure who have moderate to severe FMR.

\section{Competing interests}

$\mathrm{OB}$ and $\mathrm{SB}$ are employees of the medical consulting company Synergus $A B$, which received a grant from Cardiac Dimensions Inc. to develop a decision analytic model. MH and JL serve as proctors for Cardiac Dimensions Inc. UCH have received grant support within the AMADEUS and TITAN trials. TS was a primary investigator for clinical trials, sponsored by Cardiac Dimensions Inc. SLG is a consultant to the Cardiac Dimensions Inc. with limited stock options. NM, OVB and DGR are employees of Cardiac Dimensions Inc. with stock options.

\section{Authors' contributions}

$\mathrm{OB}$ contributed to design, data collection, analysis, and interpretation of the results and writing of the manuscript. NM, OVB and SB contributed to design, data collection, and interpretation of the results and writing of the manuscript. MH, UCH, TS, JL, SLG and DGR contributed to design, interpretation of the results and writing of the manuscript. All authors read and approved the final manuscript.

\section{Acknowledgements}

The study was sponsored by Cardiac Dimensions Inc. (Kirkland, WA, USA). The authors thank Laura Geissler, MSc for the help with the collection of the cost data, Elisabeth Burdukova, MD, MSc for help with data analysis, and Natalia Stelmaszuk, MSc for editing support. Authors also thanks Journal's reviewers, Simone Huygens and Laura Burgers, for valuable comments, which helped to improve the manuscript.

\section{Author details}

'Synergus AB, Svardvagen 19, 18233 Danderyd, Sweden. ${ }^{2}$ Medical Clinic I, Neuss City Clinic, Lukas Krankenhaus GmbH, Preußenstraße 84, 41464 Neuss, Germany. ${ }^{3}$ Department of Internal Medicine II, Paracelsus Medical University Salzburg, Müllner Hauptstr. 48, A-5020 Salzburg, Austria. ${ }^{4}$ Department of Cardiology, Interventional Cardiology, HCP Medical Center, Poznan University of Medical Sciences, ul. 28 czerwca 1956 Nr 194, 61-485 Poznan, Poland. ${ }^{5}$ Pole Sante Republique, 105 Avenue de la République, 63050 Clermont-Ferrand, France. ${ }^{6}$ Department of Cardiology, University of Washington, Seattle, WA, USA. ${ }^{7}$ Cardiac Dimensions Incorporated, 5540 Lake Washington Blvd NE, Kirkland, WA 98033, USA. ${ }^{8}$ Department of Learning Informatics, Medical Management Centre, Management and Ethics, Karolinska Institutet, Solnavägen 1, 17177 Solna, Sweden. ${ }^{9}$ Division of Pediatric Emergency Medicine, Seattle Children's Hospital, 4800 Sand Point Way NE, Seattle, WA 98105, USA.

Received: 18 November 2014 Accepted: 30 April 2015

Published online: 14 May 2015

\section{References}

1. Lancellotti P, Gerard PL, Pierard LA. Long-term outcome of patients with heart failure and dynamic functional mitral regurgitation. Eur Heart J. 2005;26(15):1528-32.

2. Baskett RJ, Exner DV, Hirsch GM, Ghali WA. Mitral insufficiency and morbidity and mortality in left ventricular dysfunction. Can J Cardiol. 2007;23(10):797-800
3. Trichon BH, Felker GM, Shaw LK, Cabell CH, O'Connor CM. Relation of frequency and severity of mitral regurgitation to survival among patients with left ventricular systolic dysfunction and heart failure. Am J Cardiol. 2003;91(5):538-43.

4. Karimov $\mathrm{JH}$, Kobayashi M, Fukamachi K. Functional mitral regurgitation: modern concepts for ventricular geometry reshaping. Expert Rev Med Devices. 2012;9(2):131-8.

5. Maisano F, La Canna G, Colombo A, Alfieri O. The evolution from surgery to percutaneous mitral valve interventions: the role of the edge-to-edge technique. J Am Coll Cardiol. 2011;58(21):2174-82

6. Crestanello JA. Surgical approach to mitral regurgitation in chronic heart failure: when is it an option? Curr Heart Fail Rep. 2012;9(1):40-50.

7. Schmitto JD, Lee LS, Mokashi SA, Bolman RM, Cohn LH, Chen FY. Functional mitral regurgitation. Cardiol Rev. 2010;18(6):285-91.

8. Raja SG, Berg GA. Moderate ischemic mitral regurgitation: to treat or not to treat? J Card Surg. 2007;22(4):362-9.

9. Ogutu P, Ahmed I, Dunning J. Should patients with asymptomatic severe mitral regurgitation with good left ventricular function undergo surgical repair? Interact Cardiovasc Thorac Surg. 2010;10(2):299-305.

10. Atluri $P$, Acker MA. Mitral valve surgery for dilated cardiomyopathy: current status and future roles. Semin Thorac Cardiovasc Surg. 2012;24(1):51-8.

11. Krishnaswamy A, Marc Gillinov A, Griffin BP. Ischemic mitral regurgitation: pathophysiology, diagnosis, and treatment. Coron Artery Dis. 2011;22(5):359-70.

12. Siminiak T, Hoppe UC, Schofer J, Haude M, Herrman JP, Vainer J, et al. Effectiveness and safety of percutaneous coronary sinus-based mitral valve repair in patients with dilated cardiomyopathy (from the AMADEUS trial). Am J Cardiol. 2009;104(4):565-70.

13. Siminiak T, Wu JC, Haude M, Hoppe UC, Sadowski J, Lipiecki J, et al. Treatment of functional mitral regurgitation by percutaneous annuloplasty: results of the TITAN Trial. Eur J Heart Fail. 2012;14(8):931-8.

14. Jerzykowska O, Kalmucki P, Woloszyn M, Smuszkiewicz P, Firek L, Siminiak T. Echocardiographic evaluation of percutaneous valve repair in patients with mitral regurgitation using the CARILLON system. Kardiol Pol. 2010;68(1):57-63.

15. Sculpher M, Drummond M, Buxton M. The iterative use of economic evaluation as part of the process of health technology assessment. J Health Serv Res Policy. 1997;2(1):26-30

16. Vallejo-Torres L, Steuten LM, Buxton MJ, Girling AJ, Lilford RJ, Young T. Integrating health economics modeling in the product development cycle of medical devices: a Bayesian approach. Int J Technol Assess Health Care. 2008:24(4):459-64

17. Ijzerman MJ, Steuten LM. Early assessment of medical technologies to inform product development and market access: a review of methods and applications. Appl Health Econ Health Policy. 2011;9(5):331-47.

18. Drummond MFSM, Torrance GW, O'Brien BJ, Stoddart GL. Methods for the economic evaluation of health care programmes. 3rd ed. Oxford: Oxford University Press; 2005.

19. Caro JJ, Briggs AH, Siebert U, Kuntz KM. ISPOR-SMDM Modeling Good Research Practices Task Force. Modeling good research practices overview: a report of the ISPOR-SMDM Modeling Good Research Practices Task Force 1. Value Health. 2012;15(6):796-803.

20. Siebert U, Alagoz O, Bayoumi AM, Jahn B, Owens DK, Cohen DJ, et al. State-transition modeling: a report of the ISPOR-SMDM Modeling Good Research Practices Task Force 3. Value Health. 2012;15(6):812-20.

21. Ford E, Adams J, Graves N. Development of an economic model to assess the cost-effectiveness of hawthorn extract as an adjunct treatment for heart failure in Australia. BMJ Open. 2012;2:e001094.

22. Cowper PA, DeLong ER, Whellan DJ, Allen LaPointe NM, Califf RM. Economic effects of beta-blocker therapy in patients with heart failure. Am J Med. 2004;116(2):104-11.

23. Rossi A, Dini FL, Faggiano P, Agricola E, Cicoira M, Frattini S, et al. Independent prognostic value of functional mitral regurgitation in patients with heart failure. A quantitative analysis of 1256 patients with ischaemic and non-ischaemic dilated cardiomyopathy. Heart. 2011;97(20):1675-80.

24. Koelling TM, Aaronson KD, Cody RJ, Bach DS, Armstrong WF. Prognostic significance of mitral regurgitation and tricuspid regurgitation in patients with left ventricular systolic dysfunction. Am Heart J. 2002;144(3):524-9.

25. Pecini R, Thune JJ, Torp-Pedersen C, Hassager C, Kober L. The relationship between mitral regurgitation and ejection fraction as predictors for the prognosis of patients with heart failure. Eur J Heart Fail. 2011;13(10):1121-5. 
26. Biermann J, Neumann T, Angermann EC, Düngen HD, Erbel R, Herzog W, et al. Resource use and costs in systolic heart failure according to disease severity: a pooled analysis from the German Competence Network Heart Failure. J Public Health. 2012;20(1):23-30.

27. Yao G, Freemantle N, Calvert MJ, Bryan S, Daubert JC, Cleland JG. The long-term cost-effectiveness of cardiac resynchronization therapy with or without an implantable cardioverter-defibrillator. Eur Heart J. 2007;28(1):42-51.

28. Federal Statistics Office (2012) Consumer Price Index [https://www.destatis. de/EN/FactsFigures/NationalEconomyEnvironment/Prices/ConsumerPrice Indices/Tables_/ConsumerPricesCategories.html?cms_gtp=151228_list\% 253D1\%2526151226_slot\%253D2\&https=1]

29. Chaplin S, Scuffham PA, Alon M, van den Boom G. Secondary prevention after PCl: the cost-effectiveness of statin therapy in the Netherlands. Neth Heart J. 2004;12:331-6.

30. Eichler HG, Kong SX, Gerth WC, Mavros P, Jonsson B. Use of cost-effectiveness analysis in health-care resource allocation decision-making: how are cost-effectiveness thresholds expected to emerge? Value Health. 2004;7(5):518-28.

31. Centre BHK. Threshold values for cost effectiveness in healthcare, KCE. 2008.

32. German National Institute for Quality and Efficiency in Health Care (IQWIG). General Methods for the Assessment of the Relation of Benefits to Costs, Version 1.0 edn, German National Institute for Quality and Efficiency in Health Care (IQWiG). 2009.

33. Siminiak T, Wu J, Haude M. Treatment of Functional Mitral Regurgitation by Percutaneous Annuloplasty. In: Heart Failure Congress: 2013. Lisbon: European Society of Cardiology; 2013.

34. Okura H, Takada Y, Kubo T, Asawa K, Taguchi H, Toda I, et al. Functional mitral regurgitation predicts prognosis independent of left ventricular systolic and diastolic indices in patients with ischemic heart disease. J Am Soc Echocardiogr. 2008;21(4):355-60.

35. Mirabel M, lung B, Baron G, Messika-Zeitoun D, Détaint D, Vanoverschelde JL, et al. What are the characteristics of patients with severe, symptomatic, mitral regurgitation who are denied surgery? Eur Heart J. 2007;28(11):1358-65.

36. lung B, Vahanian A. Percutaneous treatment of mitral regurgitation: from feasibility to clinical application? Arch Cardiovasc Dis. 2011;104(1):1-3.

37. Miller G, Randolph S, Forkner E, Smith B, Galbreath AD. Long-term cost-effectiveness of disease management in systolic heart failure. Med Decis Making. 2009;29(3):325-33.

38. Pradelli L, lannazzo S, Zaniolo $O$. The cost effectiveness and cost utility of valsartan in chronic heart failure therapy in Italy: a probabilistic markov model. Am J Cardiovasc Drugs. 2009;9(6):383-92.

39. van Hout BA, Wielink G, Bonsel GJ, Rutten FF. Effects of ACE inhibitors on heart failure in The Netherlands: a pharmacoeconomic model. Pharmacoeconomics. 1993;3(5):387-97.

40. Berry C, Murdoch DR, McMurray JJ. Economics of chronic heart failure. Eur J Heart Fail. 2001;3(3):283-91.

41. McMurray JJ, Stewart S. Epidemiology, aetiology, and prognosis of heart failure. Heart. 2000;83(5):596-602.

42. Cowie MR, Fox KF, Wood DA, Metcalfe C, Thompson SG, Coats AJ, et al. Hospitalization of patients with heart failure: a population-based study. Eur Heart J. 2002;23(11):877-85.

43. Neumann T, Biermann J, Erbel R, Neumann A, Wasem J, Ertl G, et al. Heart failure: the commonest reason for hospital admission in Germany: medical and economic perspectives. Dtsch Arztebl Int. 2009;106(16):269-75.

44. Mealing S, Feldman T, Eaton J, Singh M, Scott DA. EVEREST II high risk study based UK cost-effectiveness analysis of MitraClip ${ }^{\oplus}$ in patients with severe mitral regurgitation ineligible for conventional repair/replacement surgery. J Med Econ. 2013;16(11):1317-26.

45. Cameron HL, Bernard LM, Garmo VS, Hernandez JB, Asgar AW. A Canadian cost-effectiveness analysis of transcatheter mitral valve repair with the MitraClip system in high surgical risk patients with significant mitral regurgitation. J Med Econ. 2014;17(8):599-615.

46. Whitlow PL, Feldman T, Pedersen WR, Lim DS, Kipperman R, Smalling R, et al. Acute and 12-month results with catheter-based mitral valve leaflet repair: the EVEREST II (Endovascular Valve Edge-to-Edge Repair) High Risk Study. J Am Coll Cardiol. 2012;59(2):130-9.

\section{Submit your next manuscript to BioMed Central and take full advantage of:}

- Convenient online submission

- Thorough peer review

- No space constraints or color figure charges

- Immediate publication on acceptance

- Inclusion in PubMed, CAS, Scopus and Google Scholar

- Research which is freely available for redistribution

Submit your manuscript at www.biomedcentral.com/submit 